\title{
Pensar i veure el món a través del concepte de cicle
}

\author{
Conxita Márquez Bargalló \\ Departament de Didàctica de la Matemàtica i les Ciències Experimentals. U. Autònoma de Barcelona \\ conxita.marquez@uab.es
}

Cal reivindicar l'interès de treballar el concepte "cicle" a les diferents etapes educatives (infantil, primària, secundària), presentant algunes experiències, dificultats i reflexions entorn a alguns dels cicles que es treballen a l'ensenyament obligatori, especialment el de l'aigua.

El terme cicle forma part del vocabulari comú. Parlem del cicle de la lluna, del cicle menstrual, del cicle superior, d'un cicle de conferències, el cicle de la vida...

Però des del punt de vista de les ciències la idea de cicle té una gran importància com a expressió d'una determinada manera d'entendre el funcionament del món.

Per a les ciències un cicle és una successió de fets 0 de fenòmens que presenten una certa periodicitat en l'espai o en el temps i que constitueixen les etapes d'una evolució des d'un estat inicial fins a un estat final.

\section{PER QUÈ ENSENYAR EL CONCEPTE DE CICLE?}

$\mathrm{Hi}$ ha moltes raons per ensenyar el concepte cicle, però aquí en destacarem principalment tres:

- Perquè comporta una manera de mirar els fenòmens del món característica de la ciència.

- Perquè afavoreix maneres de pensar complexes, pròpies del pensament científic.

- Perquè és un model que ens ajuda a racionalitzar la forma d'actuar.

\section{Una manera de mirar els fenòmens}

La ciència és una manera de mirar el món i de pensar-hi. Es fonamenta en l'assumpció que el món natural es comporta d'una manera consistent i predictible; per aquest motiu el principal objectiu de les ciències és el de conèixer els patrons o models de comportament del món natural que tinguin poder explicatiu i predictiu.

El cicle és una manera potent de mirar, pensar i organitzar molts tipus de canvis ja que ens permet mostrar les regularitats i lleis que els regeixen. Al mateix temps ens permet fer prediccions: el dia que començarà la primavera, quan podrem veure al cel la constel-lació d'Orió, quan estarà a punt la collita...

\section{Maneres complexes de pensar}

Si en treballar un procés cíclic amb els alumnes i les alumnes ens fixem en:

- les fases o estadis que el componen,

- els canvis que es donen entre un estadi i el següent,

- les causes d'aquests canvis,

estem afavorint les seves capacitats d'anàlisi i de síntesi, ja que busquem les regularitats, la conservació i l'estabilitat que un canvi cíclic reflecteix. Unes maneres de pensar que van més enllà de les quotidianes.

La imatge gràfica, un cercle tancat, amb la qual solen associar-se els cicles, fa pensar en un ordre i en connexions precises, quan en realitat les relacions entre els diferents estadis són molt més complexes i múltiples. Aquesta és una altra idea potent: constatar que els cicles no són una seqüència lineal causa-efecte de fenòmens, sinó que en els processos que representem hi ha canvis simultanis, canvis reversibles, interaccions, petits cicles dins d'un gran cicle... Són sistemes d'una gran comple- 
xitat que la idea de cicle ajuda a convertir en manejable.

En plantejar situacions que requereixen una interpretació -on no tot sigui tan lineal com que una causa té un únic efecte o que un fenomen és degut a una sola causa- s'entrena als nois i noies en l'ús de formes de pensament pròpies del pensament científic (multicausa i multiefecte).

Una altra característica dels cicles és que normalment ens comuniquen la informació utilitzant conjuntament el llenguatge verbal i el llenguatge visual. Ara bé, aquesta manera de representar té uns codis i uns símbols que cal conèixer i treballar amb els alumnes. Fixem-nos en la gran varietat de gruixos, colors, i formes de les fletxes que solen aparèixer en les representacions dels cicles, per pensar que cal ensenyar a llegir adequadament els elaborats codis del llenguatge visual que hi utilitzem.

\section{Model que ajuda a racionalitzar la forma d'actuar}

Com a ciutadans i ciutadanes se'ns demana que fem recollida selectiva, que reciclem, que reduïm el consum de matèries, que no embrutem l'aigua...

Per entendre el per què d'aquestes demandes necessitem haver construït el concepte de cicle dels materials. I per entendre el per què de l'extinció d'algunes espècies o per poder argumentar les nostres actuacions per preservar-les necessitem haver construït el concepte de cicle de vida dels organismes i conèixer els factors que posen en perill la seva continuittat, com a base per a una actuació responsable.

\section{UN EXEMPLE: \\ MIRAR, PENSAR I REPRESENTAR LA VIDA EN UNA BASSA}

Des de la biologia ens pot interessar estudiar la vida a la bassa. Per això s'hauran d'identificar alguns dels éssers vius que hi viuen, el seu règim alimentari, i intentar establir les relacions tròfiques.

Una primera manera de mirar és la que intuïtivament fan els alumnes, en termes de predació on, per exemple, la garça reial (GR) es menja la carpa (C); aquesta es menja el cap gros (CG), aquest les plantes aquàtiques (PA) i aquestes les sals minerals (SM). La representació gràfica d'aquesta manera de mirar és una línea o cadena, en la qual les fletxes signifiquen qui menja a qui.

$$
\begin{aligned}
& \mathrm{GR} \longrightarrow \mathrm{C} \longrightarrow \mathrm{CG} \longrightarrow \mathrm{CA} \longrightarrow \mathrm{PM} \\
& (\longrightarrow=\text { menja })
\end{aligned}
$$

Quan es demana als nois i noies si hi pot haver alguna relació o tancament entre els extrems de la cadena es troben amb un problema: veuen clarament que no poden seguir la mateixa lògica ja que les substàncies minerals no mengen garces!

Aquesta manera de mirar la vida de la bassa no permet fer una representació cíclica (fig. 1):

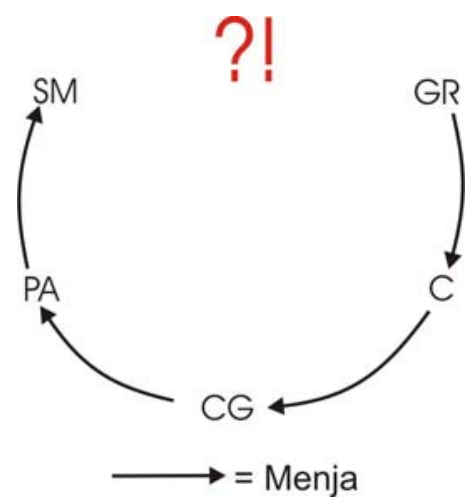

Figura 1. Amb la relació “...menja..." no és possible tancar el cicle.

Per poder representar el cicle de vida cal aprendre a mirar la bassa en termes de transferència de matèria entre els diferents nivells tròfics (fig. 2).
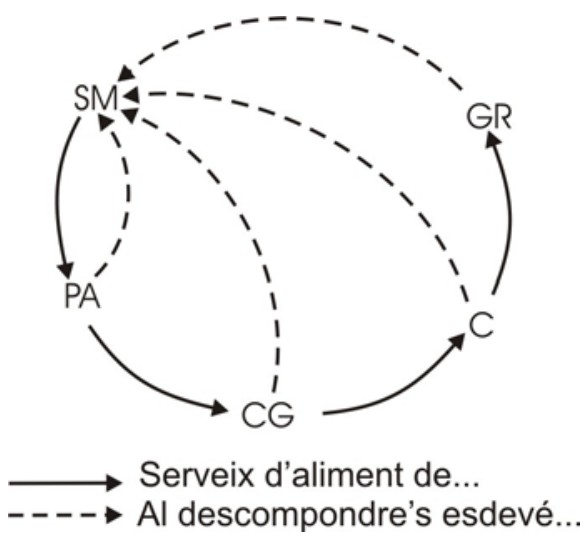

Figura 2. La representació de fluxos de matèria permet tancar el cicle.

Així, algunes de les consideracions decidides per un grup de nens i nenes de cinquè de primària que els van permetre canviar la lògica de les relacions i, per tant, fer-se una representació del cicle de vida a la bassa, van ser:

- Tots els ésser vius de la bassa s'alimenten de forma dependent els uns dels altres.

- Les plantes verdes absorbeixen "substàncies minerals" a través de les arrels. 
- Després de la seva mort tots els éssers vius es descomponen en fragments elementals (substàncies minerals).

Aquestes consideracions varen permetre refer la representació de la vida a la bassa en termes de cicle de la matèria.

\section{EXPERIÈNCIES, DIFICULTATS I REFLEXIONS EN L'APRENENTATGE ESCOLAR D'ALGUNS CICLES}

Si ens demanessin quins són els cicles que es treballen a l'escola obligatòria crec que fàcilment ens posaríem d'acord i que els podríem agrupar en tres grans blocs: els cicles estacionals, els cicles biològics i els cicles dels materials (roques, aigua, carboni, paper...)

\section{Els cicles estacionals}

En la regularitat que suposen les estacions, els alumnes han d'aprendre a relacionar uns canvis (els estacionals que poden percebre) amb un altre canvi (la posició relativa de la Terra i el Sol al llarg de l'any). Això els permet explicar els canvis que observem i els dóna la possibilitat de fer-hi prediccions (fig. 3).

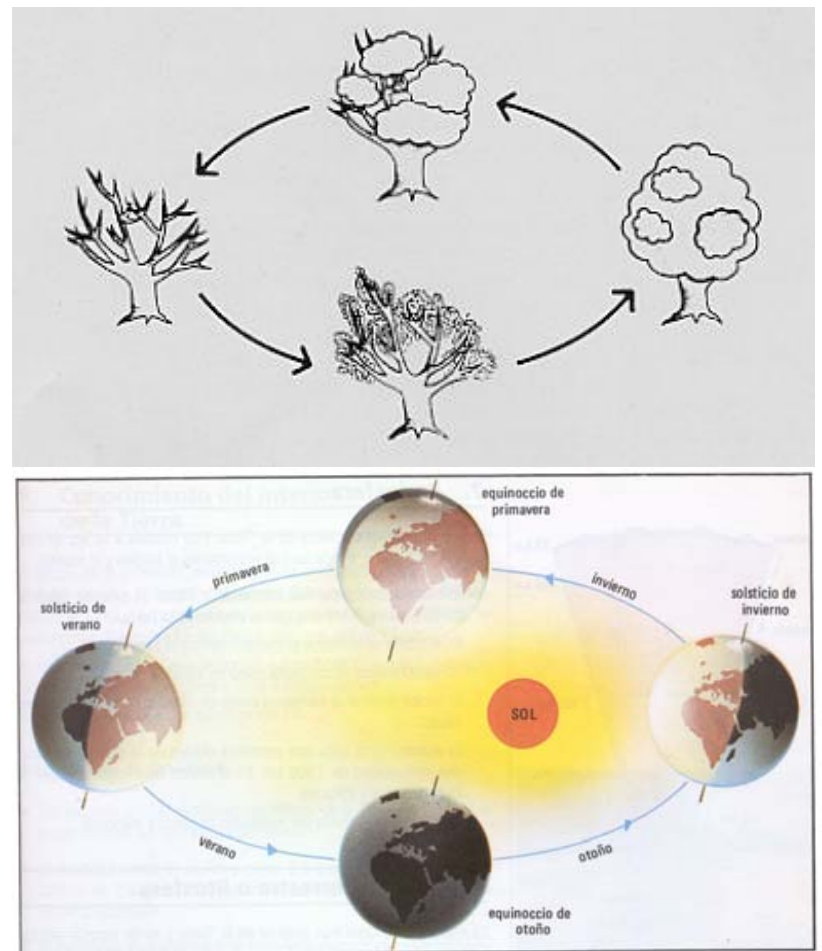

Figura 3. Els canvis estacionals (a dalt) s'han d'aprendre a relacionar amb els canvis en la posició relativa de la Terra i el Sol (a baix).
Per a un infant no és senzill representar-se de manera coherent la successió de les quatres estacions. En efecte, els fenòmens als quals assistim se succeeixen de manera gradual i contínua i s'adapten malament a una subdivisió rígida en un nombre definit de períodes. És important aprendre a fer aquest procés a partir d'observacions directes. Finalment cal plantejar activitats d'aplicació del model per entrar en el joc, sempre incert, de predir el futur i inferir el passat.

\section{Els cicles biològics}

Els canvis de qualsevol ésser viu en el temps són allò que ens porta al concepte de cicle vital.

El procés en realitat és continu, però se sol subdividir en estadis successius: naixement, creixement, desenvolupament, maduresa i vellesa.

En un cicle vital hi ha un canvi doble en el temps: el lineal i el cíclic. Així, en la successió lineal i que pot ser representada per un conjunt d'episodis relacionats amb cadenes rectilínies s'incorpora la idea i la representació cíclica quan es vol reflectir que aquests canvis es produeixen de manera recurrent al llarg del temps (fig. 4).

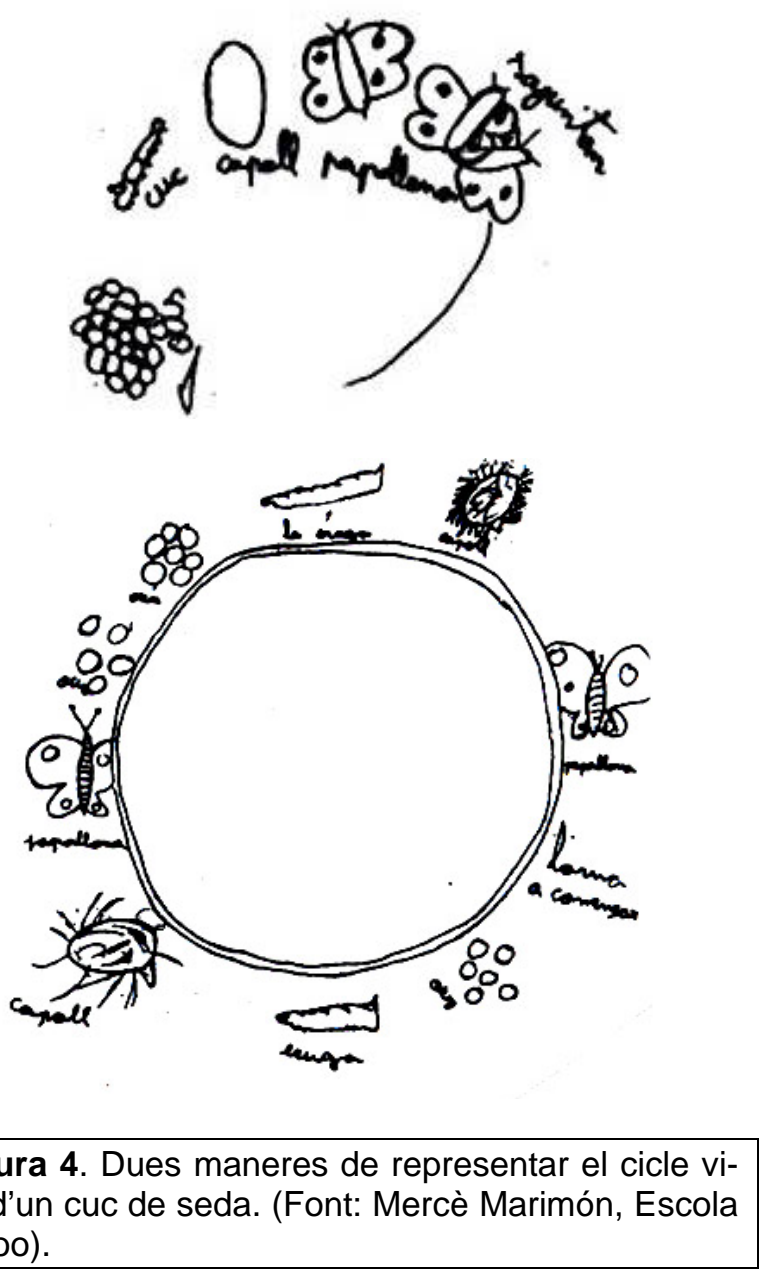


Una representació convencional del cicle vital d'un organisme podria començar amb un gàmeta masculí o un gàmeta femení per obtenir un ou 0 embrió que passarà per diferents etapes: infant, jove, adult (mascle o femella) i començar de nou.

El retorn, que indiquem sovint amb una fletxa, representa una abstracció; és una manera de representar que torna a passar el mateix, però no essent res exactament el mateix.

També en el cas de la representació dels cicles vitals hi ha la dificultat de saber quines són les fases significatives del cicle: per què en el cicle vital del cuc de seda hi ha quatre estadis (ou, cuc, capoll, papallona) i no més (ou, cuc petit, cuc gran, capoll a mig fer, capoll fet...)

Determinades preguntes poden ajudar a construir el concepte de cicle vital d'un ésser viu:

- Com és? Com era? Com serà? Com és que el podem reconèixer si canvia constantment?

- Què necessita un organisme per mantenir la vida en cada moment del cicle?

- Què intercanvia un organisme amb el medi en cada moment del cicle?

- Com 'es regula' l'organisme per respondre a les variacions del medi en cada moment del cicle?

\section{El cicle dels materials}

Un altre gran grup de cicles que es treballen a l'escola són els cicles dels materials: el cicle de les roques, el del paper, el vidre, els plàstics... En cursos més alts, el cicle del carboni, el del nitrogen, de l'oxigen, etc. El que gairebé mai no falta és el cicle de l'aigua.

A tall d'exemple es presenten algunes preguntes relacionades amb el cicle dels materials, que ajuden a construir aquesta manera de mirar, on es vol destacar que malgrat els canvis hi ha sempre una conservació de la matèria.

- D'on ve? A on va? En algun moment el "d'on ve" i l' "a on va" es troben? Què pot passar si no es troben?

- Podem seguir la pista als canvis d'un material?

- Què passa amb un material quan ja no el fem servir? Què li passa al paper, al plàstic, a un metall, al menjar...?

- Aquesta làmina de ferro -o de plàstic, paper, menjar...-, què era abans? I abans? I abans? I després, en què es transformarà? I després? I després?... Podríem tornar a l'inici, fer un cicle?

- A la natura, hi ha cap material que desaparegui?

- Quan de temps triga un material a canviar (a fer el cicle)? Tots els materials triguen el mateix?

- Tota la matèria és en circulació?

\section{El cicle de l'aigua}

En general, quan es demana als alumnes què és el cicle de l'aigua comenten que és aquell dibuix on hi ha el mar, una muntanya i núvols. Evidentment, el cicle de l'aigua no és només un dibuix i els nois i noies l'haurien d'entendre com un model o explicació que els permet comprendre uns fets quotidians en relació a la circulació de l'aigua a la natura, així com predir el seu funcionament i racionalitzar la seva forma d'actuar.

L'observació de fets quotidians com la pluja, les fluctuacions del cabal d'un riera, una font natural dalt d'una muntanya, les coves amb aigües subterrànies... poden plantejar preguntes en relació a com circula l'aigua a la natura. A les classes de ciències, les preguntes i l'activitat de recerca de respostes afavoreix l'evolució dels models explicatius inicials dels alumnes vers els models explicatius complexos de la ciència.

El cicle de l'aigua que s'explica actualment a les escoles i als centres de secundària és un "model" que no va sorgir de cop i volta. Abans d'aquest model hi va haver diferents explicacions o teories discutides fins que al segle XVIII, a partir de dades experimentals i quantitatives, es van establir les bases del que actualment entenem per cicle de l'aigua.

Per afavorir aquesta visió del cicle de l'aigua com a model explicatiu seria convenient modificar la manera habitual de plantejar el seu estudi.

Caldria presentar el cicle de l'aigua com una interpretació, des de la perspectiva científica, de com circula l'aigua a la natura, i estudiar-lo (mirar-lo) com un sistema en el que hi ha uns components (en aquest cas magatzems d'aigua), una dinàmica (uns canvis) i un funcionament general complex.

El que proposem és el següent:

1) Partir de l'observació de l'entorn natural, perquè constitueix un sistema físic on es donen un conjunt de fenòmens relacionats amb l'aigua que plantegen una sèrie de preguntes del tipus: Per què surt aigua d'una font natural? Per què cada vegada els rius porten menys aigua, segons diuen els pagesos? Per què els rius porten aigua malgrat que fa dies que no plou?

2) Per començar a buscar l'explicació i a construir el model caldrà identificar els diferents components d'aquest sistema:

- Els components espacials del sistema, és a dir, les localitzacions o els magatzems d'aigua a la natura (atmosfera, oceans, glaceres...) i els diferents estats físics en què la trobem.

- Els components dinàmics del sistema, és a dir, els fluxos o els processos que s'esta- 
bleixen quan l'aigua canvia d'estat o de Iloc (circulació superficial, subterrània, evaporació...)

- El funcionament del sistema, és a dir, quines són les causes dels diferents canvis i quines són les peculiaritats del model cíclic de l'aigua.

3) Aplicar el model, és a dir, utilitzar el model per representar algunes situacions reals similars a les plantejades inicialment.

En aquest procés de construcció del model és de gran interès fer que els alumnes es plantegin preguntes en relació amb la circulació de l'aigua a la natura: De què estan formats els núvols? Hi ha aigua a l'aire? Com ho sabem? D'on ve l'aigua de la pluja? D'on ve l'aigua de les fonts que trobem dalt de al muntanya? Com és que el mar no augmenta de nivell malgrat que hi arribin tants rius? Com és que els rius tenen aigua quan no plou?

S'ha vist que cal plantejar preguntes que promoguin la idea de quantificació i per tant de conservació. Per exemple: és suficient l'aigua de la pluja per omplir els grans rius? L'aigua que bevien els dinosaures és la mateixa que bevem nosaltres?

Algunes de les dificultats més habituals en relació al cicle de l'aigua són:

- No tancar el cicle (fig. 5), el que comporta no explicitar que la quantitat total d'aigua a la terra es conserva.

- Considerar un cicle només atmosfèric (l'aigua s'evapora, condensa i plou) oblidant per tant la importància de la circulació continental i la intervenció dels éssers vius en el cicle.

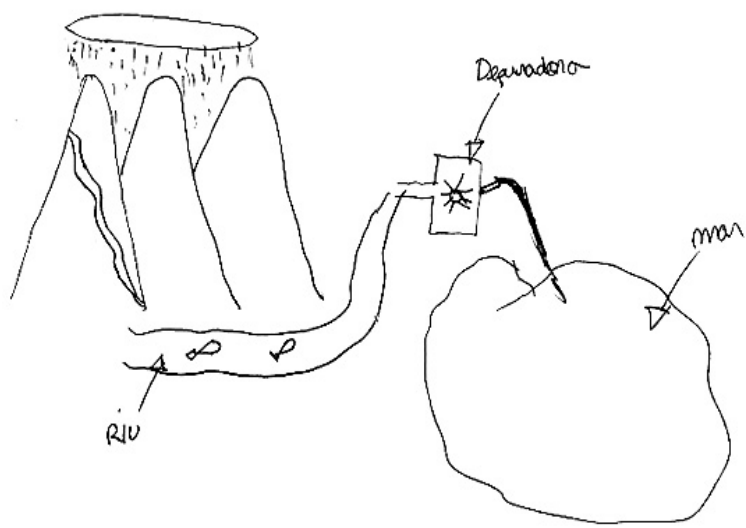

Figura 5. Una de les dificultats més habituals de l'alumnat en relació al cicle de l'aigua: no tancar el cicle.

- Representar l'aigua subterrània com a bosses similars a les del petroli (fig. 6) i sobretot desconnectades totalment del circuit de l'aigua.

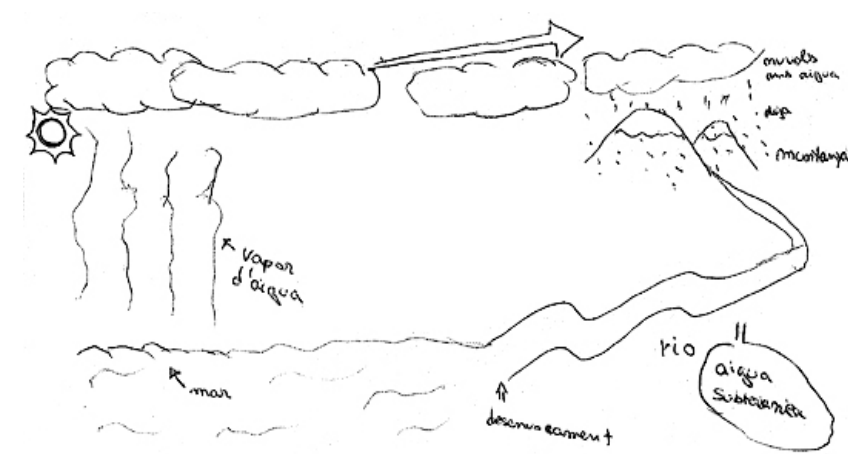

Figura 6. Una altra de les dificultats de l'alumnat davant el cicle de l'aigua: representar l'aigua subterrània en bosses similars a les del petroli, desconnectades del circuit de l'aigua a la natura.

- Representar l'aigua subterrània de manera similar a la superficial, amb rius d'aigua blava circulant pel subsòl. Aquest tipus de representació dificulta la comprensió de les diferents velocitats de circulació de l'aigua superficial i subterrània i dificulta poder respondre preguntes del tipus: com és que encara hi ha aigua al pou si fa dies que no plou?

- Localitzar la pluja a la muntanya i l'evaporació al mar. Aquesta representació, però, és la que apareix en la majoria dels llibres de text.

- Ambigüitats en l'ús i significat de les fletxes.

- Més facilitat en explicar els canvis per "escalfament" que per "refredament". En les "històries d'una gota d'aigua" que escriuen els alumnes es constata que acostumen a explicar les causes dels canvis d'estat que impliquen absorció d'energia, però no els que es relacionen amb pèrdua d'energia. Hem comprovat que milloren amb l'aplicació de jocs en els quals simulen ser gotes d'aigua que absorbeixen o deixen anar energia.

- Aquestes dificultats es reprodueixen en el cas de treballar el cicle urbà de l'aigua. Identificar els components espacials (magatzems d'aigua a la ciutat), els components dinàmics (canvis de magatzem, fluxos d'energia) i el funcionament general, promou una millor comprensió del recorregut de l'aigua a la ciutat i permet identificar la problemàtica associada al gran consum d'aigua i sobretot a la gran despesa energètica que suposa mantenir el subministrament d'aigua en bones condicions. Treballar la interconnexió entre el cicle natural i l'urbà promou el desenvolupament de valors ambientals en l'alumnat.

\section{Finalment}

Ensenyar ciències implica ensenyar a pensar a través de "potents" models que serveixen per inter- 
pretar molts fenòmens diferents. El model "cicle" n'és un dels més importants.

És a partir de models com aquests que la ciència ens permet de comprendre canvis que tenen lloc al planeta -tant els naturals com els provocats per l'ésser humà-, i ens pot ajudar a prendre decisions per actuar coherentment.

"Molta gent no entén que el món natural no és un món lliure de la manera que els occidentals entenen la llibertat. El món natural funciona segons lleis naturals $i$ hi ha molts cicles del món natural amb els quals s'ha de viure en harmonia". (Wovoka, cabdill pell-roja).

\section{BIBLIOGRAFIA}

BACH, J; BRUSI, D (1990). El cicle de l'aigua. Perspectiva Escolar, 150, 8-19.

MÁRQUEZ, C (2000). El ciclo del agua. Actividades alternativas. Uso de los recursos naturales. Guía Praxis para el profesorado. Ciencias de la Naturaleza. ESO.

MÁRQUEZ,C; IZQUIERDO,M; ESPINET, M. (2003). Comunicación multimodal en la clase de ciencias: el ciclo del agua. Enseñanza de las ciencias, 21 (3), 371-386.

PUJOL, RM. (2003). Didáctica de las ciencias en la educación primaria. Madrid: Ed Síntesis.

SANMARTÍ, N. (2002). Didáctica de las ciencias en la educación secundaria obligatoria. Madrid: Ed. Síntesis. 